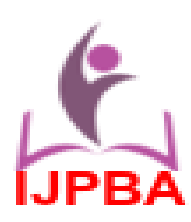

Contents lists available at www.ijpba.in

International Journal of Pharmaceutical and Biological Science Archive

PubMed (National Library of Medicine ID: 101738825)

Index Copernicus Value 2017: 71.80

Volume 7 Issue 5; September-October; 2019; Page No. 28-33

\title{
A COMPARATIVE STUDY OF YOGIC AND AYURVEDIC INTERVENTION IN THE MANAGEMENT OF TAMAKA SHWASA.
}

\section{Dr Arpan A. Bhatt ${ }^{1}$, Dr Shweta Pandey ${ }^{2}$, Dr Brajesh Singh ${ }^{3}$, Dr Gauravi Vyas ${ }^{4}$, Dr Gyanendra Datta Shukla ${ }^{5}$,} Dr Upasna ${ }^{6}$

${ }^{1}$ Professor, Swasthvrutta Vibhaga, Gulab Kunwerba Ayurved Mahavidalaya, Gujarat Ayurved university Jamnagar Gujarat

${ }^{2}$ Assistant professor, P.G. Department of Kayachikitsa, Rishikul Campus, Haridwar, Uttarakhand Ayurveda University, Dehradun

${ }^{3}$ Assistant Professor, Morarji Desai National Institute of Yoga, New Delhi.

${ }^{4}$ Lecturer, Maharashi Patanjali Institute of Yog and Naturopathy Education and Research, Gujarat Ayurved university Jamnagar Gujarat.

${ }^{5}$ Associate Professor, P.G. department of Panchakarma, Gurukul Campus, Haridwar, Uttarkhand Ayurved University, Dehradun.

${ }^{6}$ PG Scholar, P.G. Department of Kaya Chikitsa, Rishikul Campus, Haridwar, Uttarakhand Ayurved University, Dehradun.

Conflicts of Interest: Nil

Corresponding author: Dr. Shweta Pandey

\begin{abstract}
Abstract

Asthma is one of the commonest respiratory disease (as Jamnagar situated on sea coast has more moisture present in the air and polluting environment is increasing due to rapid industrial development i.e. industries using various chemicals/ pollutants, increases the incidences of Respiratory tract diseases) as well as a significant disease burden worldwide costing billions of dollars. The WHO estimates that there are between 15 and 20 million people with Asthma in India. The increase is likely to be particularly dramatic in India, which is projected to become the world's most populous nation by 2050 . An absolute $2 \%$ increase in the prevalence of Asthma in India would result in an additional 20 million people with the disease. Anti-asthmatic drugs that are available in the market are expensive and have adverse effects. Thus, it is wise to look for an adjunct therapy to alleviate these problems. Therefore, the main aim of this study is to see the effect of Yoga on patterns of clinical features, peak expiratory flow rates and use of drugs in Asthmatic patients.

Yoga intervention group (Group A) showed $70.58 \%$ reduction in the use of emergency medicine while it was $68.09 \%$ in Ayurvedic conventional group (Group B). There was a $24.93 \%$ increment in the PEFR in the Group A while only $16.49 \%$ in the Group B. There was statistically significant reduction in frequency and duration of Asthma attacks in both the Groups. Yoga exercise among Asthmatic patients resulted in a decreased number of attacks and use of drugs. It also shows significant improvement in the peak expiratory flow rate in Yoga intervention Group. Further large scale study is recommended.
\end{abstract}

Keywords: Asthma, Yoga, Expiratory flow rate.

\section{INTRODUCTION}

Asthma is a chronic (long-term) lung disease that inflames and narrows the airways by spastic contraction of the smooth muscle in the bronchioles, which partially obstructs the bronchioles and causes recurring periods of wheezing, Chest tightness, shortness of breath, and coughing. ${ }^{i}$ ii Though the prevalence and incidence of Asthma is difficult to assess with certainty because of lack of reliable population based figures which used uniform diagnostic criteria, however, it has been suggested that approximately $5 \%$ of adult and
$7-10 \%$ of children in USA and Australia have the disorder. ${ }^{\text {iii }}$ According to the CDC (centre for disease control) report, 10-11 million persons had acute attacks in 1998, which results in 13.9 million outpatient visits, 2 million request for urgent care, and 423,000 hospitalizations, with a total cost of $>6$ Billion USD. ${ }^{\text {iv }}$ In Africa, it accounts for $2-10 \%$ of medical admissions ${ }^{v}$ The WHO estimates that there are between 15 and 20 million people with Asthma in India. ${ }^{\text {vi }}$ The increase is likely to be particularly dramatic in India, which is projected to become the world's most populous nation by 2050 . An absolute $2 \%$ increase in the prevalence of Asthma in India 
would result in an additional 20 million people with the disease.

Yoga, or its ancestor, first appeared somewhere around 5,000 years ago. Since then, it has gradually evolved in to the modern form. The word "Yoga" means union, joining or to link together as one whole according to Sanskrit language. Hath yoga is a physical method which uses the breath to link the various parts of the body and the mind and to allow them to behave as one functional unit which helps in the control of Asthma. ${ }^{\text {vii viii }}$

It was found that one preliminary study of yoga therapy for Asthma on 46 patients data clearly shows a significant qualitative improvement in the severity and duration of attacks; attacks per week and decrease medication use. ${ }^{\text {ix }}$

Significant symptomatic improvement after Yoga training for 9 months in patients with chronic severe airways obstruction was observed in Australia. A decade ago both short and long-term prospective studies in India showed clearly the beneficial effects of yoga in the management of bronchial Asthma. ${ }^{\times}$A study showed significant effect within short time practice. $^{\mathrm{xi}}$

Since Bronchial Asthma is an important cause of morbidity and mortality especially in resource limited areas where the long term use of multiple drugs is costly, it is wise to think alternative way to treat such an illness with better economic safety and avoid adverse effect of the drugs. The study therefore tries to look into the applicability of Yoga as an alternative approach in the treatment of Asthma.

\section{Material and Methods}

The study was conducted at the Swasthavrutta department of Gujarat Ayurved University in Jamnagar town, Gujarat. A clinical trial, controlled prospective study was conducted by randomly dividing patients into intervention (Yoga intervention) group and control (Ayurvedic conventional) group. Yoga exercise was given every day for 60 minutes for 16 weeks by a yoga trainer.

The training included;

INTEGRATED YOGA PRACTICE- This was made to practice by the patient at the

1. PRAYER 25.0

2. STRENGTHENING EXERCISES (sakti vikasaka suksma vyayama)

Greeva Shakti Vikasaka Prathama, Dwitiya, Trutiya

Vakshasthala Shakti Vikasaka Prathama, Dwitiya

Udara Shakti Vikasaka Prathama, Dwitiya, Trutiya

3. YOGASANAS

STANDING ASANAS:

Tadasana, Urdhvahastottanasana, Ardha Chakrasana, Katichakrasana PRONE ASANAS

Bhujangasana Dhanurasana

SITTING ASANAS

Ushtrasana Shashankasana Uttanamundukasana

Matsyendrasana / Vakrasana Kapalabhati

SUPINE ASANAS

Uttanpadasana Ardhahalasana Viparitakarani / Halasana Setubandhasarvangasana Matsyasana Shavasana

4. PRANAYAMA

Nadi Shodhana Ujaayi Bhramari Aumkara Dharana

5. SHUDDHI KRIYA: (to be done once in a week)

Kunjal Sutraneti Kapalabhati mins

10

$\min$

\section{5 rounds}

5 rounds

5 rounds

30.0

mins

10

mins

5.0

mins

10

mins

5.0

mins

mins 
Dr Arpan A. Bhatt et al, Journal of Pharmaceutical and Biological Science Archive

62 patients diagnosed to have asthma and being supported in Swasthavrutta department of Gujarat Ayurved University in Jamnagar town, Gujarat who volunteered to take part in the study participated.

\section{Inclusion criteria:}

- Belonging to age group 24-60 years.

- Having the sign and symptoms of Bronchial Asthma (Tamaka Shwasa) as given below:

- Shwasa Kashtata-Breathlessness

- Kasa-Coughing

- Parshvashula - Pain in flanks

- Ghurghurakam - Wheezing

- Feeling of Chest tightness/ compression

- Uncomplicated cases of Bronchial Asthma.

- Chronicity less than 10 years.

- Willing and able to participate as well as understanding and affirming to sign a written consent for the treatment schedule of the concerned study.

\section{Exclusion criteria:}

Patient falling under the following criteria will be excluded from the study:

- Age below 24 years and above 60 years.

- Patients who are having Thrombosis, Stroke, and other severe abnormalities like Cardiac disease, Renal disorders, AIDS, Endocrine disorders like Diabetes Mellitus, Thyroidism etc.

- Other complicated respiratory disease i.e. Swine Flue, Tuberculosis, COPD etc. and having any organic lesion such as tumour or any anatomical defect in the airways will be excluded from the study.

\section{Observation and Results-}

62 patients who fulfil the inclusion criteria and signed the consent randomly categorized as yoga and control group.

Table 1: Socio-demographic characteristics of Asthmatic patients.

\begin{tabular}{llll}
\hline \multirow{2}{*}{ Socio - Demographic Features } & Frequency & \\
\cline { 3 - 4 } Sex & Male & 18 & Group B \\
\multirow{3}{*}{ Age } & Female & 14 & 12 \\
& $\mathbf{2 1 - 3 0}$ & 05 & 18 \\
& $\mathbf{3 1 - 4 0}$ & 10 & 01 \\
& $\mathbf{4 1 - 5 0}$ & 07 & 03 \\
\multirow{3}{*}{ Occupation } & $\mathbf{5 1 - 6 0}$ & 10 & 12 \\
& Labour & 01 & 14 \\
& Service & 09 & 08 \\
& Business & 09 & 05 \\
& House wife & 13 & 01 \\
\hline
\end{tabular}

Table 2: Mean changes in the subjective and objective Parameter before and after the Yoga exercise in Asthmatic patients.

\begin{tabular}{lllll}
\hline Mean changes & Group A & $\begin{array}{l}\text { P } \\
\text { Value }\end{array}$ & $\begin{array}{l}\text { Group } \\
\text { B }\end{array}$ & $\begin{array}{l}\text { P } \\
\text { Value }\end{array}$ \\
\hline Shwasakashtata- Frequency & & $<0.001$ & 01.37 & $<0.001$ \\
Shwasakashtata -duration of attack & 01.66 & $<0.001$ & 01.27 & $<0.001$ \\
No. of emergency medicine taken & 01.89 & $<0.001$ & 01.33 & $<0.001$ \\
Kasa (Coughing) & 01.28 & $<0.001$ & 00.92 & $<0.001$ \\
Kapha Shthivanam (Expectoration) & 01.04 & $<0.001$ & 00.86 & $<0.001$ \\
Ghurghurkam (Wheezing) & 01.09 & $<0.001$ & 01.31 & $<0.001$ \\
Asino Labhate Saukhyam & 01.34 & $<0.001$ & 01.39 & $<0.001$ \\
Pinasa(Rhinitis) & 01.65 & $<0.001$ & 00.68 & $<0.001$ \\
Chest tightness & 01.04 & $<0.001$ & 01.24 & $<0.001$ \\
\hline
\end{tabular}




\begin{tabular}{lllll}
\hline Parshvashula (Pain in flanks) & 01.26 & $<0.001$ & 01.00 & $<0.001$ \\
Lalate Sweda (Perspiration on fore head) & 01.68 & $<0.001$ & 01.00 & $<0.001$ \\
Bhrama (Giddiness) & 01.00 & $<0.010$ & 00.94 & $<0.001$ \\
PEFR & 00.52 & $<0.050$ & 00.28 & $>0.050$ \\
(SpO $)_{2}$ by Pulse Oximetry & 01.07 & $<0.001$ & 00.50 & $<0.010$ \\
Absolute Eosinophil Count & 87.84 & $<0.001$ & 88.63 & $<0.001$ \\
Chest expansion at the level of nipple & 02.85 & $<0.001$ & 01.63 & $<0.001$ \\
ACQ(Asthma control Questionnaire) & 06.56 & $<0.001$ & 06.70 & $<0.001$ \\
\hline
\end{tabular}

Most of the subjects in the yoga group, showed a decreased number of day attacks per week and night attacks per month as compared to the control group $(P<0.05)$. Mean change in the PEFR was 0.52 in the yoga group whereas 0.28 in the control group which was statistically significant $(P<0.05)$ and statistically insignificant $(P>0.05)$ respectively. Mean change in the ACQ was 6.56 in the yoga group whereas 6.70 in the control group which was statistically significant $(P<0.001)$.Similar pattern was also observed in the mean change of pulse Oximetry, Chest expansion, Absolute Eosinophil Count and other symptoms among the two groups $(P<0.001)$.

\section{Discussion}

- This study showed a reduction in asthma attacks in the yoga group which is comparable to the previous research work. ${ }^{\mathrm{xii}}$ The decrease in the number of attacks resulted in the reduction of use of asthma drugs which is comparable to the previous study where it showed decrement in the use of oral asthma medications for the acute attacks. The improvement in peak expiratory flow rate in this study is also comparable to the previous studies.

- This explains the effect of yoga in the relief of asthma attack and improving the quality of life. The responsiveness of air ways is noticeably increased in asthma patients so that they develop bronchoconstrictions for smaller amount of physicochemical stimuli than the healthy ones. There is a complex interplay of several factors: inherent responsiveness of smooth muscles, abnormality in autonomic nervous control and breakdown in airway defences may promote bronchial hyper reactivity. So, reducing the hyperresponsiveness of the patients will benefit them to have good outcome in the control of their asthma. The other way is the psychological effect on asthma progression, though the mechanism is complex and not well understood; still psychological factors affect about half of all patients. This was the focus pointed to be improved by the yoga exercise and shown improvement at different studies.

- In the observations of 62 patients of Tamaka Shwasa, maximum no of patients i.e., $38.70 \%$ were belonging to the age group of $51-60$ years, $51.61 \%$ were of female sex. $24.19 \%$ patients were primary educated, $22.58 \%$ patients were graduate. $46.77 \%$ patients were 46.77 housewives. $20.96 \%$ patients were addicted to tobacco chewing and $04.83 \%$ addicted for Alcohol.

- Maximum, $64.51 \%$ of patients were taking Madhura Rasa dominant diet; each of $82.25 \%$ showed the etiological factor as Raja and mental disturbance, $100 \%$ patients were addicted to tea. $58.06 \%$ were having Krura Koshtha, $30.64 \%$ of the patients reported disturbed sleep.

- Aggravating factors $-80.64 \%$ of the patients reported increased in symptoms due to Shita Aahara-Vihara. 82.25\% reported Raja as aggravating factor. $61.29 \%$ reported increased frequency of attacks during rainy season. In $70.96 \%$ of patients, asthma attack was observed in early morning.

- Ushna Aahara-Vihara was reported as relieving factor in $80.64 \%$ of the patients.

- Other observations chronicity of the disease in $69.35 \%$ of the patients was between 5-10 years. $67.74 \%$ of the patients were reported gradual Onset, $45 \%$ were Sthula Samhanana.

\section{- Cardinal Symptoms:}

All the 62 patients complained Shwasakashtata. Ghurghurakam was found in $96.77 \%$ of the patients. $87.09 \%$ noticed Asinolabhate Saukhyam. $83.87 \%$ reported with Kasa, Kaphastheevana was found in $77.41 \% .72 .58 \%$ of the patients had Lalate Sweda. Pinasa was complained by $67.74 \%$. $61.29 \%$ presented with Parshvagraha.

\section{Effect of therapy:}

- Duration of Shwasakashtata -In the Yoga group (Group A) Shwaskashtata was relieved up to $76.38 \%$, in the (Group B) Shwasakastata was relieved up to $58.46 \%$ both the groups showed statistically highly significant. But in the percentage 
Group A shows better relief in comparison to Group B.

- Frequency of Shwasakashtata- $73.52 \%$ reduction was in Group A, 57.75\% was in Group B both the groups showed statistically highly significant. But in the percentage Group A shows better relief in comparison to Group B.

- Reduction in taking no of emergency medicine $-70.58 \%$ in Group A and in Group B it was $68.09 \%$.Both the Groups showed statistically highly significant result.

- Pinasa- 51.02 \% relief was found in Group A and $42.50 \%$ relief in Group B. Both the Groups showed statistically highly significant result.

- Kaphashtheevana - 50\% relief were observed in Group A while $47.02 \%$ were relieved by Group B. Both the Groups showed statistically highly significant result,

- Cough-72.97\% relief was observed in Group A, $51 \%$ relief Group B. Both the Groups showed statistically highly significant result.

- Ghurghuraka- $64.81 \%$ relief was observed in Group A, 60 \%, relief Group B. Both the Groups showed statistically highly significant result. In percentage GroupA shows better relief in comparison to Group B.

- Orthopnea (Asino Labhate Saukhyam) - 80.00 $\%$ relief in Group A showed statistically highly significant, 69.64 \% relief in Group B showed statistically highly significant result. In percentage Group A shows better relief in comparison to Group B.

- Parshvashula- $82.60 \%$ relief was obtained in Group A, while it was $56.41 \%$ in Group B. Both the Groups showed statistically highly significant result.

- Lalate Sweda- $90.24 \%$ relief was found in Group A, while it was $60.60 \%$ in Group B. Both the Groups showed statistically highly significant result. In percentage Group A shows better relief in comparison to Group B.

- Result on PEFR - was increased $24.93 \%$ in Group A which was statistically significant. In Group B- PEFR was increased by $16.49 \%$ which was statistically insignificant.

- Result on AEC - AEC was reduced in Group A by $24.72 \%$ which was statistically highly significant. In Group B AEC was reduced by 23.57 which were statistically significant.

- Results on Oxyhemoglobin saturation (SpO2) by Pulse Oximetry:

Oxyhemoglobin saturation is increased in Group A by $01.12 \%$ which was statistically highly significant.

In Group B- Oxyhemoglobin saturation was increased by $0.51 \%$ which was statistically highly significant.

\section{- Results on chest expansion}

Chest expansion is increased in Group A by $76.79 \%$, $70.95 \% 58.77 \%$ at the level of Axilla, Nipple and Xiphoid respectively. This was statistically highly significant. In Group B Chest expansion was increased $31.88 \%, 41.88 \%$ and $47.09 \%$ at the level of Axilla, Nipple and Xiphoid respectively. This was statistically highly significant. In percentage Group A shows better relief in comparison to Group B.

In comparative study between Yogic interventional group and Ayurvedic conventional group:

- The statistical analysis showed that, Group A, gave better result in Shwasakashtata-Duration of attack, Lalate Sweda and Pulse Oximetry in comparison to Group-B.

- Obtained difference between the two groups in Shwasakashtata-Duration of attack, Lalate Sweda and Pulse Oximetry found statistically, significant $(P<0.05)$, significant $(P<0.01)$ and highly significant $(P<0.001)$ respectively. Difference in rest symptoms and investigation like PEFR, A C Q, Abs. E. Count., Spirometry between both the groups was statistically insignificant $(P>0.05)$.

- In conclusion, this study showed that Yoga decreased the number asthma attacks, use of drugs and improvement in the peak flow rate. We recommend conducting large scale study on the effect of yoga on Asthma.

Acknowledgement- The study was approved by scientific committee of ACYER and the ethical committee of University and according to the guidelines of MDNIY some changes are being incorporated. Participants were given information about the study objective, voluntary participation and told to their treatment. They were also told about the activities that are going to be practiced and were also informed as they can withdraw from participation at any stage. Those who signed the consent form participated in the study.

\section{Reference}

1. ' Paul-Erik Paulev. The Respiratory system. In: Jensen Jens Ingeman, Madsen Joop, SiggaardAndersen Ole, Lynggaard Margrethe., editors. Online Text book in medical physiology and pathophysiology essential and clinical problems. Copenhagen Medical Publishers, pharmapedia books; 1999-2000.

2. ii The Glossary Committee of the international union of physiological sciences (IUPS), author 
"Glossary on respiratory and gas exchange" J Appl physiol. 1973;35:941-961. [PubMed]

3. iii MC Fadden ER. Asthma. In: Fauci Anthony S., editor. Harrison's principle of Internal Medicine. 16th edition. New York: McGraw Hill Inc; 2005. pp. 635-649.

4. iv Ethio Rlliot F. Allergic disorders. In: Behrman, Jenson, Stanton, Kleigman, editors. Nelson text book of pediatrics. 13th edition. McGraw Hill Inc. New growth; 1989. pp. 945-950.

5. ${ }^{\prime}$ Bayu T, Warrel DA, Femi-Pearse D. The Lung. In: parry Eldryd, Godfrey Richard, Mabey David, Gill Geoffrey., editors. Principles of Medicine in Africa. 2nd edition. Oxford: Oxford University Press; 1984. pp. 761-816.

6. vi http://en.wikipedia.org/wiki/Asthma

7. vii Saraswati Swami Shankardevananda. Lecture at $2^{\text {nd }}$ international Doctor's symposium, Ganga Darshan, Australia. 2006. Asthma: Its diagnosis and treatment.

8. viii Brena SF. Yoga and Medicine. New York: Julian press inc; 1972

9. ${ }^{i x}$ Nagarathna R. Preliminary studies of yoga therapy for bronchial asthma. Bangalore, India: Vivekanada Kendra yoga research foundation; 2002.

10. ' Vedanthan PK, kesavalu Lakshmayya N, Murphy Krishna C, Duvall Kirby, Hall Mary J, Baker Sheila, Nagarathna S. Allergy and asthma proc. Vol. 19. Colorado: Northern Colorado allergy and asthma clinic; 1998. Clinical study of yoga techniques in university students with asthma: a control study; pp. 3-9.

11. Ki Khannam AA, Sachdeva U, Guleria R, Deepak KK. Study of pulmonary and autonomic functions of asthma patients after yoga training. Indian journal physiol pharmacol. 1996;40(4):318-324. [PubMed]

12. xii Negendra HR, Nagarathna R. An integrated approach of yoga therapy of bronchial Astama: A 354 month prospective study. Journal of Asthma. 1986;23(3):123-137. [PubMed] 